\title{
Die Natur.
}

Natur I Wir sind von ihr umgeben und umschlungen - unvermögend, aus ihr herauszutreten, und unvermögend, tiefer in sie hinein za kommen. Ungebeten und ungewarnt nimmt sie uns in den Kreislauf ihres Tanzes auf und treibt sich mit uns fort, bis wir ermüdet sind und ihrem Arme entfallen.

Sie schafft ewig neue Gestalten; was da ist, war noch nie; was war, kommt nicht wieder; alles ist neu und doch immer das Alte.

Wir leben mitten in ihr und sind ihr fremd. Sie spricht unaufhörlich mit uns und verrät uns ihr Geheimnis nicht. Wir wirken beständig auf sie und haben doch keine Gewalt über sie.

Sie scheint alles auf Individualität angelegt zu haben, und macht sich nichts aus den Individuen. Sie baut immer und zerstört immer, und ihre Werkstätte ist unzugänglich.

Sie lebt in lauter Kindern; und die Mutter, wo ist sie? Sie ist die einzige Künstlerin: aus den simpelsten Stoffen zu den größten Kontrasten: ohne Schein der Anstrengung zu der gröBten Vollendung. zur genauesten Bes:immtheit, immer mit etwas Weichem überzogen. Jedes ihrer Werke hat sein eigenes Wesen, jede ihrer Erscheinungen den isoliertesten Begriff, und doch macht alles eins aus.

Sio spielt ein Schauspiel; ob sie es selbst sieht, wissen wir nicht, und doch spielt sie's für uns, die wir in der Ecke stehen.

Es ist ein ewiges Leben, Werden und Bewegen in ihr, und doch rückt sie nicht weiter. Sie verwandelt sich ewig, und ist kein Moment Stillstehen in ihr. Fürs Bleiben hat sie keinen Begriff, und ihren Fluch hat. sie ans Stillstehen gehängt. Sie ist fest: ihr Tritt ist gemessen, ihre Ausnahmen selten, ihre Gesetze unwandelbar.

Gedacht hat sie und sinnt beständig; aber nicht als ein Mensch, sondern als Natur. Sie hat sich einen eigenen allumfassenden Sinn vorbehalten, den ihr niemand abmerken kann.

Dio Menschen sind all' in ihr und sie in allen. Mit allen treibt sie ein freundliches Spiel und freut sich, je mehr man ihr abgewinnt. Sie treibt's mit vielen so im Verborgenen, daß sie's zu Ende spielt, ehe sie's merken.

Auch das Unnatürlichste ist Natur. Wer sie nicht allenthalben sieht, sieht sie nirgendwo recht.

Sie liebt sich selber und haftet ewig mit Augen und Herzen ohne Zahl an sich selbst. Sie hat sich auseinandergesetzt, um sich selbst zu genießen. Immer läßt sie neue Genießer erwachsen, unersättlich, sich mitzuteilen.

Sie freut sich an der Illusion. Wer diese in sich und andern zerstört, den straft sie als der strengste Tyrann. Wer ihr zutraulich folgt. den drückt sie wie ein Kind an ihr Herz. 
Ihre Kinder sind ohne Zahl. Keinem ist sie zuberall karg, aber vie hat Lieblinge, an die sie viel verschwendet und denen sie viel aufopfert. Ans Grobe hat sie ihren Schutz geknúptt.

Sie spritzt ihre Geschopfe aus dem Nichts hervor und sagt ihnen nicht, woher sie kommen und wohin sie gehen. Sie sollen nur laufen. Die Bahn kennt sie.

Sie hat wenige Triebfedern, aber nie abgenutzte, immer wirksam, immer mannigfaltig.

Ihr Schauspiel ist immer neu, weil sie immer neve Zuschauer schafit. Leben ist ihre schønste Erfindung, und der Tod ist ihr Kunstgriff, viel Leben zu haben.

Sie gibt Bedürnisse, weil sie Bewegung liebt. Wunder, daB sie alle diese Bewegung mit wenigem erreicht. Jedes Bedurfnis ist Wohltat. Schnell befriedigt, schnell wieder erwachsend. Gibt sie eins mehr, so ist's ein neuer Quell der Lust; aber sie kommt bald ins Gleichgewicht.

Sie setzt alle Augenblicke zum längsten Lauf an und ist alle Augenblicke am Ziel.

Sie ist die Eitelkeit selbst; aber nicht für uns, denen sie sich zur grobten Wichtigkeit gemacht hat.

Sie läßt jedes Kind an sich künsteln, jeden Toren über sich richten, Tausende stumpf uber sich hingehen und nichts sehen, und hat an allen ihre Freude und findet bei allen ihre Rechnung.

Man gehorcht ihren Gesetzen, auch wenn man ihnen widerstrebt; man wirkt mit ihr, auch wenn man gegen sie wirken will. Bio macht alles, was sie gibt, zur Wohltat; denn sie macht es erst unentbehrlich. Sie säumt, da B man sie verlange; sie eilt, daB man sie nicht satt werde.

Sie hat keine Sprache noch Rede, aber sie schafft Zungen und Herzen, durch die sie fühlt und spricht. Ihre Krone ist die Liebe; nur durch sie kommt man ihr nahe. Sie macht Klüfte zwischen allen Wesen, und alles will sich verschlingen. Sie hat alles isoliert, um alles zusammenzuziehen. Durch ein paar Züge aus dem Becher der Liebe hält sie für ein Leben voll Mühe schadlos.

Sie ist alles. Sie belohnt sich selbst und bestraft sich selbst, erfreut und quält sich selbst. Sie ist rauh und gelinde, lieblich und schrecklich, kraftlos und allgewaltig. Alles ist immer da in ihr. Vergangenheit und Zukunft kennt sie nicht. Gegenwart ist ihre Ewigkeit. Sie ist gütig. Ich preise sie mit allen ihren Worken. Sie ist weise und still. Man reißt ihr keine Erklärung vom Leibe, trutzt ihr kein Geschenk ab, das sie nicht freiwillig gibt. Sie ist listig, aber zu gutem Ziele, und am besten ist's, ihre List nicht zu merken.

Sie ist ganz, und doch immer unvollendet. So wie sie's treibt, tann sie's immer treiben. Jedem erscheint sie in einer eigenen Crestalt. Sie verbirgt sich in tausend Namen und Termen und ist immer dieselbe.

Sie hat mich hineingestellt, sie wird mich auch herzusfohren. Ich vertraue mich ihr. Sio mag mit mir schalten; sie wird ihr Werk nicht hessen. Ich sprach nicht von ihr; nein, was wahr ist und was falsch ist, alles hat sie gesprochen. Alles ist ihre Schuld, alles ist ihr Verdienst.

Goethe (1780). 
